\title{
Magnesium and liver disease
}

\author{
Meixi Liu, Huayu Yang, Yilei Mao \\ Department of Liver Surgery, Peking Union Medical College (PUMC) Hospital, PUMC \& Chinese Academy of Medical Sciences, Beijing 100730, \\ China \\ Contributions: (I) Conception and design: MX Liu, YL Mao; (II) Administrative support: None; (III) Provision of study materials or patients: None; \\ (IV) Collection and assembly of data: MX Liu, HY Yang; (V) Data analysis and interpretation: All authors; (VI) Manuscript writing: All authors; (VII) \\ Final approval of manuscript: All authors. \\ Correspondence to: Yilei Mao. Department of Liver Surgery, Peking Union Medical College (PUMC) Hospital, PUMC \& Chinese Academy of \\ Medical Sciences, Beijing 100730, China. Email: yileimao@126.com.
}

\begin{abstract}
Magnesium is a vital cation that takes part in many cellular processes. Magnesium balance can be disturbed in multiple conditions, and differences in magnesium concentration can be responsible for numerous physiological and pathological processes. Magnesium deficiency is commonly associated with liver diseases, and may result from low nutrient uptake, greater urinary secretion, low serum albumin concentration, or hormone inactivation. In turn, low magnesium content in serum and liver tissue can lead to the progression of these diseases, due to a disruption in mitochondrial function, defective protein kinase $\mathrm{C}(\mathrm{PKC})$ translocation, inflammatory responses, oxidative stress, or metabolic disorders. Furthermore, magnesium supplementation can improve liver function in certain liver diseases. This paper comprehensively reviews the changes in magnesium concentrations associated with liver cirrhosis, alcoholic liver disease (ALD), liver cancer, and viral hepatitis, and explains how such changes may in turn impact these disease processes.
\end{abstract}

Keywords: Magnesium; liver cirrhosis; alcoholic liver disease (ALD); viral hepatitis; inflammatory response

Submitted Sep 04, 2019. Accepted for publication Sep 11, 2019.

doi: 10.21037/atm.2019.09.70

View this article at: http://dx.doi.org/10.21037/atm.2019.09.70

\section{Introduction}

Magnesium is the second most abundant intracellular ion and the fourth most abundant cation in the body (1). It is widely distributed in almost all parts of the body and is highly compartmentalized, being present within the nucleus, cytoplasm, mitochondria, and endoplasmic reticulum $(2,3)$. Magnesium plays an important role in lots of cellular processes, including DNA replication and repair, intermediary metabolism, ion transportation, cell proliferation, and signal transduction (4). Food and hard water are the main sources of body magnesium $(5,6)$, which is vital for numerous physiological and pathological conditions. Magnesium deficiency can result from a number of diseases or the administration of certain medications, and can in turn predispose to many diseases, such as cardiovascular diseases, diabetes, and mental disorders (1).
The liver is one of the most vital organs, being involved in many aspects of metabolism, immune responses, and the synthesis of complex biomolecules. In addition, it regulates the transportation and distribution of many trace elements, including magnesium (3). The relationship between magnesium levels and liver disease is intriguing: in many liver diseases, patients are magnesium deficient, while insufficient magnesium levels in turn aggravate these diseases (3,7-9). In fact, every $100 \mathrm{mg}$ increase in magnesium intake is associated with a $49 \%$ decrease in the risk of mortality due to all liver diseases (10).

Liver cirrhosis, alcoholic liver disease (ALD), liver cancer and viral hepatitis are common liver diseases. This review provides an overview of the differences in magnesium concentration associated with these diseases and whether such differences might affect disease processes. 


\section{Magnesium and liver cirrhosis}

\section{Cirrbosis is characterized by magnesium deficiency}

Liver cirrhosis is the end stage of a variety of liver diseases, and is characterized by the disruption of liver structure, fibrosis, and the formation of regenerative nodules (11). Patients with liver cirrhosis usually have low body magnesium levels (12-14). Since our understanding of the mechanisms involved in magnesium homeostasis has improved, it has been shown that both serum and cellular magnesium levels are significantly lower in cirrhosis patients (3). Several mechanisms may account for this situation. Liver function is impaired in cirrhosis, and some patients develop portal hypertension, resulting in the development of gastroesophageal varices and intestinal edema. Magnesium supply may be poor because of malnutrition and lower absorption in the distal jejunum. In addition, the liver synthesizes albumin, which is an important transporter of magnesium in the circulation. Serum albumin decreases significantly in cirrhosis patients, such that magnesium transportation and balance may be disturbed. The inactivation of many hormones also takes place in the liver, and if this function is impaired, the resulting higher serum levels of aldosterone, growth hormone, and glucagon enhance the excretion of urinary magnesium. In addition, magnesiuric diuretics (such as furosemide) are often used in cirrhotic patients to alleviate ascites, but this also increases the excretion of magnesium into the urine (15). Finally, many cirrhosis patients have a long history of alcohol intake, and magnesium deficiency is universally recognized in chronic alcoholics (8). The mechanism of this association will be explored below.

\section{Magnesium insufficiency aggravates cirrbosis}

It was shown by Rayssiguier that hepatic magnesium loss is associated with greater collagen deposition in the liver (16). This observation might suggest that a decrease in hepatic magnesium content may lead to the aggravation of hepatic cirrhosis. Among patients with liver diseases, only $15-20 \%$ progress to cirrhosis (8). Thus, although investigations are lacking to date, there is a significant possibility that the patients that progress to cirrhosis may be those with particularly abnormal hepatocyte magnesium concentrations.

A number of studies have focused on exploring the reason why low magnesium levels result in the deterioration of liver cirrhosis.
As is widely known, magnesium is highly compartmentalized, being present in mitochondria in particular, where it is an important cofactor involved in metabolic function. In cirrhosis, a reduction in intracellular magnesium content has a negative impact on mitochondrial bioenergetics, which heavily depend on the appropriate intramitochondrial magnesium concentration $(17,18)$. When mitochondrial function is impaired, oxidation in the hepatocyte is affected, which is associated with a $17 \%$ reduction in ATP production and hepatocyte damage. The subsequent liver repair process leads to additional fibrosis and worsens the cirrhosis.

Recent studies have found that (protein kinase C $\varepsilon$ ) PKC $\varepsilon$ can regulate fibrinogen deposition, and although these findings were made in cardiac tissue $(19,20)$, this enzyme may also regulate fibrinogen deposition in the liver. The PKCs are a family of protein kinase enzymes that regulate the function of many cellular proteins. Activated PKC translocation induces the accumulation of magnesium within the cell, and PKCe displays the highest affinity for magnesium (21). An $\mathrm{Mg}^{2+}$ concentration of $1 \mathrm{mM}$ is enough for PKC $\varepsilon$ activation and translocation, and is well within the normal concentration range of free cytoplasmic $\mathrm{Mg}^{2+}(22)$. Hence, it may be that lower magnesium concentrations in cirrhosis patients would lead to the defective translocation of PKC $\varepsilon$ to the cell membrane, which in turn would result in lower $\mathrm{Mg}^{2+}$ accumulation within the hepatocyte. This further reduction in cytoplasmic magnesium would exacerbate the reduction in $\mathrm{PKC} \varepsilon$ activity, generating a positive feedback loop. This decrease in $\mathrm{PKC} \varepsilon$ translocation and activity in liver cells increases fibrinogen and collagen deposition, which aggravates cirrhosis.

In the 1930 s, clinical signs of inflammation were observed in magnesium-deficient rats (7), which displayed erythema, hyperemia, and splenomegaly (23). Thereafter, many investigators have recognized these pathologies in association with inflammation (24-27). In blood, the most prominent effect is leukocytosis, which may arise from cellular hyperplasia in the bone marrow and higher levels of substance P $(28,29)$. In the liver, there is greater infiltration with leukocytes and macrophages, the activities of both of which are improved in magnesium-deficient animals (30), along with that of Kupffer cells. As a consequence, IL-6 concentration rises and stress-induced overproduction of TNF- $\alpha$ is apparent (31).

The underlying mechanisms of the inflammatory response in magnesium deficiency are not clear, but the following events may be involved (32-34). Firstly, the 


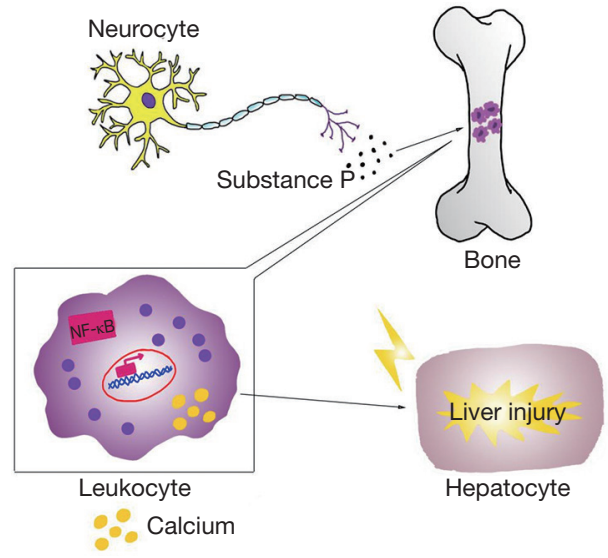

Figure 1 Mechanisms of the inflammatory response mediated liver injury in magnesium deficiency. Magnesium deficiency activates neuroendocrinological pathways and increases the production of neuromediators, such as substance P. Elevated substance P results in leukocytosis in the bone marrow. Decreased magnesium lead to further activation of these leukocytes through increased intracellular calcium and regulation of $\mathrm{NF}-\kappa \mathrm{B}$, which then move to the liver and cause liver injury. NF- $\kappa \mathrm{B}$, nuclear factor- $\kappa \mathrm{B}$.

activation of inflammatory cells is involved in signal transduction, in which intracellular $\mathrm{Ca}^{2+}$ plays a vital role. We have observed that in vitro stimulation leads to a greater $\mathrm{Ca}^{2+}$ response (35). However, magnesium is a natural calcium antagonist (36); therefore, it is likely that a lower extracellular magnesium concentration would lead to an increase in intracellular calcium, triggering inflammation. Consequently, oral magnesium administration and higher intracellular magnesium concentrations may have beneficial anti-inflammatory effects $(37,38)$. Secondly, the induction of inflammation by magnesium deficiency should be considered alongside the role of neuromediators, which are also important in inflammation. Mental stress alone can incite an inflammatory response (39), but in addition, the nervous and immune systems interact with one another. Magnesium deficiency initiates a systemic stress response by activating neuroendocrinological pathways, through greater production of neuromediators, such as substance $\mathrm{P}$ (33), which can cause an inflammatory response. Thirdly, the activation of nuclear factor- $\kappa \mathrm{B}(\mathrm{NF}-\kappa \mathrm{B})$ may be one of the major mechanisms whereby an inflammatory response is initiated due to magnesium deficiency. The NF$\kappa \mathrm{B}$ family consists of a group of transcription factors that are crucial in the regulation of inflammatory responses, through regulation of inflammatory gene expression, including that of numerous cytokines (40). Inappropriate regulation of NF- $\mathrm{BB}$ is involved in a wide range of inflammatory disorders. However, there is specific evidence for a role in the effects of magnesium deficiency, because Altura et al. (34) found that in cultured canine cerebral vascular smooth muscle cells, decreased extracellular magnesium concentrations induce lipid peroxidation and the activation of NF-kB.

When the magnesium content of liver cells is low, leukocytes and macrophages become very active locally, releasing many inflammatory cytokines and recruiting more inflammatory cells to the liver (30). This inflammatory response causes damage to liver cells and the repair process that follows involves fibrosis, which aggravates liver cirrhosis (Figure 1).

Previous studies have shown that reactive oxygen species (ROS) play a crucial role in hepatic fibrogenesis $(3,7,8)$. Various liver injuries, caused for example by alcohol abuse, hepatitis B virus (HBV) infection, or chronic cholestasis, can increase hepatic ROS concentrations. ROS are directly fibrogenic, because they stimulate the proliferation and activation of hepatic stellate cells (HSCs). HSCs are the main cell type responsible for fibrosis in the liver. Quiescent HSCs are desmin-positive perisinusoidal cells, which are also responsible for the storage of vitamin A. Once stimulated, quiescent HSCs transform to activated myofibroblasts, becoming the main pro-fibrotic cell type and producing type I collagen, which is the key extracellular matrix component in the liver $(11,41)$.

Activation of HSCs is the result of the presence of free radicals and lipid peroxidation products, which activate mitogen-activated protein kinase (MAPK) pathways, NF- $\mathrm{\kappa B}$ signaling, and c-myb. Greater expression of fibrosis-related genes, including those encoding transforming growth factor- $\beta 1$ (TGF- $\beta 1), \alpha$-smooth muscle actin ( $\alpha$-SMA), and type I collagen, are found in activated HSCs. TGF- $\beta 1$ is one of the key pro-fibrotic cytokines that is mitogenic in HSCs $(42,43)$. It also activates the Smad-signaling pathway and can cause hepatic fibrosis experimentally (44). The administration of antioxidants, such as $\alpha$-tocopherol, can prevent such fibrosis.

\section{Magnesium as an anti-cirrbotic therapy}

Having established that magnesium deficiency can aggravate liver cirrhosis, it is of interest whether magnesium intake 
could ameliorate this pathology. In vivo studies have shown that magnesium administration can alleviate cirrhosis, with both acetylcysteine magnesium and magnesium lithospermate B (MLB) having similar effects $(44,45)$. After 8 weeks' treatment with acetylcysteine magnesium, TGF- $\beta 1$, nitric oxide, total (tNOS) and inducible (iNOS) nitric oxide synthase levels were significantly lower in cirrhotic tissue, and hepatic lymphocyte infiltration and formation of pseudolobuli were alleviated (46). In a rat model of cirrhosis, serum alanine aminotransferase (ALT) and aspartate aminotransferase (AST) levels were significantly lower following oral MLB administration. This was because MLB strongly suppressed $\mathrm{H}_{2} \mathrm{O}_{2}$-induced ROS generation and inhibited NF- $\kappa \mathrm{B}$ transcriptional activation in HSCs. In addition, it suppressed platelet-derived growth factor (PDGF)-induced HSC proliferation and expression of $\alpha$-SMA, TGF- $\beta$, and type I collagen (46). These results suggest that magnesium might have potential as a novel therapy for liver cirrhosis.

Few studies have investigated the association between magnesium level and viral hepatitis. The only report we have identified showed that magnesium supplement can prevent $\mathrm{HCV}$ replication by binding to hepatitis $\mathrm{C}$ virus NS3 helicase (47).

\section{Magnesium deficiency and ALD}

\section{Alcobol intake causes magnesium loss}

Chronic alcohol abuse remains one of the most important causes of liver disease $(48,49)$. ALD is one of a class of diseases caused by excessive alcohol intake, ranging from fatty liver to alcoholic hepatitis and alcoholic cirrhosis. Fatty liver (alcoholic steatosis) is the most common syndrome and the earliest type of ALD, and is characterized by the excessive accumulation of lipid inside hepatocytes. It is benign and reversible, seldom progressing to alcoholic hepatitis and cirrhosis. Alcoholic hepatitis (alcoholic steatohepatitis) is a more severe type of ALD, and is characterized by hepatocyte injury, accompanied by acute or chronic inflammation. About $40 \%$ of such patients will progress to alcoholic cirrhosis, a form of the liver cirrhosis mentioned above. In ALD, serum ALT, AST, and $\alpha$-glutamyltransferase (GGT) concentrations are usually high, and the serum levels of these enzymes are often used as markers for the diagnosis of ALD.

Clinical magnesium deficiency is now recognized frequently among ALD patients, not only in the serum, but also intracellularly (8), with the degree of deficiency being directly proportional to the severity of the disease. Experimental research has shown that consumption of $6 \%$ ethanol in water for 3 weeks leads to a marked decrease in total tissue magnesium content in rats (50). Urinary magnesium excretion increases 2-3-fold upon alcohol consumption, and this occurs independently of glomerular filtration rate, renal plasma flow, or the administration of magnesium diuretics $(3,51)$. The greater renal excretion of magnesium might be the result of greater lactate production and the accumulation of organic acids, which form complexes with magnesium and impair its reabsorption in the renal tubules (52). Another explanation is that alcohol or its intermediate metabolites might have a direct effect on magnesium transporters in the renal tubular membrane (3).

Recently, evidence has accumulated which indicates that two magnesium transporter systems exist in the plasma membrane of all eukaryotic cells: $\mathrm{Na}^{+}$-dependent and $\mathrm{Na}^{+}-$ independent transporters $(2,22)$. Eukaryotic cells tightly control magnesium transport across the plasma membrane through these two kinds of transporters, under a variety of physiological conditions. These transporters involve channels (TRPM6 and TRPM7), solute transport carriers (SLC41-A1 and A2), and other proteins (e.g., MagT1, MMgT1, MMgT2 and ACDP2) (53). The $\mathrm{Na}^{+}$-dependent $\mathrm{Mg}^{2+}$ transporter is a $\mathrm{Na}^{+} / \mathrm{Mg}^{2+}$ exchanger that is activated via a cAMP-dependent pathway (54-56), and can also operate in reverse mode (57).

Alcohol consumption is associated with a reduction in liver $\mathrm{Mg}^{2+}$ content (58). Acute alcohol administration affects the $\mathrm{Na}^{+} / \mathrm{Mg}^{2+}$ exchanger as follows. It affects $\mathrm{G}$ protein signaling, leading to greater cAMP generation within hepatocytes, which activates the PKC pathway and disrupts $\mathrm{PKC} \varepsilon$ translocation to the cell membrane (59-61), resulting in greater magnesium extrusion via the $\mathrm{Na}^{+} / \mathrm{Mg}^{2+}$ exchanger. Biochemical analysis also indicates that $\mathrm{Mg}^{2+}$ loss by hepatocytes is the result of a decrease in cellular ATP concentrations $(62,63)$, which is consistent with magnesium deficiency being characterized by markedly lower $\mathrm{Mg}^{2+}$ content in the mitochondria and cytoplasm, the two main cellular compartments containing both $\mathrm{Mg}^{2+}$ and ATP (64). Chronic alcohol administration results in an impairment of the function of both $\mathrm{Na}^{+}$-dependent and $\mathrm{Na}^{+}$-independent $\mathrm{Mg}^{2+}$ transporters (by 75\%) $(50,65)$. The same defect in $\mathrm{PKC} \varepsilon$ translocation is observed, and the magnesium deficiency is associated with a $17 \%$ decrease in cellular ATP concentration (50). 


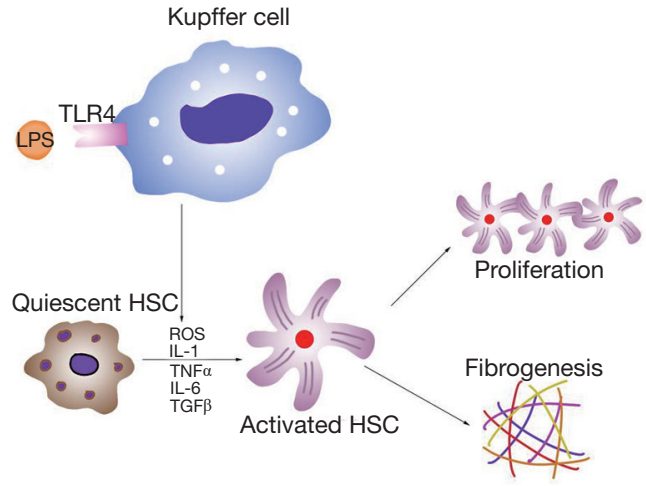

Figure 2 The role of Kupffer cells and HSCs in progression of ALD. In ALD patients, high levels of circulating LPS bind to TLR4 and activate Kupffer cells in liver. A large amount of ROS and pro-inflammatory cytokines (TNF- $\alpha$, TGF- $\beta$, IL-1 and IL-6) are generated and released. When received oxidative and inflammatory stimulation, quiescent HSCs transform into activated HSCs, resulting in HSCs self-proliferation and fibrogenesis. HSC, hepatic stellate cell; ALD, alcoholic liver disease; LPS, lipopolysaccharide; TLR4, toll-like receptor type 4; ROS, reactive oxygen species; IL, interleukin.

\section{Magnesium deficiency worsens ALD}

ALD patients suffering magnesium deficiency have been shown in both in vitro and in vivo studies to be more sensitive to septic shock during endotoxin infection $(31,35)$. After endotoxin stimulation, magnesium-deficient phagocytic cells demonstrate a stronger immune response, which is consistent with the higher death rate observed in magnesium-deficient rats (31).

Other studies have also found that ALD patients have high levels of circulating endotoxins (66). In magnesium deficient liver, endotoxin activates Kupffer cells through toll-like receptor type 4 (TLR4), and these cells play a key role in the inflammatory responses in the liver. In activated Kupffer cells, a large amount of ROS is generated by the enzyme nicotinamide adenine dinucleotide phosphate (NADPH) oxidase, which becomes the main source of ROS in the liver (67). Pro-inflammatory cytokines, such as TNF- $\alpha$, TGF- $\beta$, interleukin (IL)- 1 and IL- 6 , as well as the chemokine IL-8, are also released from activated Kupffer cells $(68,69)$. Of these cytokines, TNF- $\alpha$ is the key mediator of ALD. ROS and cytokines activate HSCs and accelerate the progression of ALD to the cirrhotic stage (Figure 2). Magnesium administration before an endotoxin challenge can reduce the severity of the disease condition and improve survival rate in rats (31). In addition, magnesium treatment decreases serum GGT and AST in alcoholic patients (70). Thus, we strongly recommend magnesium supplementation in ALD patients to prevent septic shock and slow disease progression.

Impairment in fatty acid and glucose metabolism is a key component of the pathogenesis of ALD, which initially manifests as alcoholic steatosis. Although it has been shown that alcohol can directly impair fatty acid oxidation and glucose metabolism, recent studies have also found that low magnesium content is another cause of the metabolic disorders present in ALD patients (71).

Fatty acid oxidation mainly takes place in mitochondria, and magnesium is an important cation for mitochondrial oxidative function. Low mitochondrial magnesium affects the nicotinamide adenine dinucleotide (NAD) H/NAD+ redox potential in liver, which in turn impairs fatty acid oxidation and tricarboxylic acid cycle activity $(31,33)$. Indeed, in magnesium deficiency, obvious defects are the marked increase in triglyceride levels and the reduction in the concentration of serum high density lipoproteins (HDL) (71). An accumulation of triglyceride-rich lipoproteins (TGRLP), which is associated with a marked increase in plasma apo B concentration, is also observed (72). The reduction in HDL is accompanied by lower plasma levels of both apo E and apo A1. In addition, experiments have shown there are complex changes in the expression of genes involved in lipid metabolism in magnesiumdeficient rats (72). The lipid metabolism disorder resulting from magnesium deficiency may also be related to the inflammatory response, because the same condition has been observed in rats with activated immune responses (73).

In terms of glucose metabolism, large epidemiologic studies have shown an association between lower serum magnesium and insulin resistance (74,75). Recent studies have also shown that magnesium deficiency aggravates insulin resistance, because of the associated inflammatory response and oxidative stress $(76,77)$.

In summary, magnesium deficiency in ALD patients represents a significant additional factor that can further disrupt normal metabolism and cause greater lipid deposition, both in the liver and other tissues.

\section{Magnesium and liver cancer}

Magnesium is an enzyme cofactor involved in the DNA repair mechanisms which plays a major role maintain genomic stability and fidelity. It has critical roles in the 
modulation of cell cycle progression, cell proliferation, differentiation, and apoptosis. Magnesium deficiency could therefore cause dysfunction of these systems, leading to DNA mutations, which may result in tumorigenesis $(1,4)$.

The relationship between liver cancer and body magnesium content has not been fully established, so whether liver cancer leads to reductions in serum and tissue magnesium concentrations is still unknown. However, we have shown that magnesium supplementation can protect the liver and reduce the morbidity and mortality associated with liver cancer (78).

An in vitro study has shown that magnesium cantharidate has an inhibitory effect on human hepatoma SMMC-7721 cell proliferation by blocking the MAPK signaling pathway. Specifically, the phosphorylation levels of C-jun N-terminal kinase (JNK) and extracellular signal-related kinase (ERK) decrease significantly upon treatment (79).

Magnesium plays a vital role in inhibiting the progression of HBV infection to hepatocellular cancer (HCC). HBV infection remains one of the most frequent cause of HCC in the world $(80,81)$. Once an infection is established, the viral regulatory protein hepatitis $B$ virus $X(\mathrm{HBx})$ amplifies the TGF- $\beta$ signal, which works as a tumor promoter to induce epithelial-mesenchymal transition (EMT), enhancing cancer metastasis and invasion by HCC. However, magnesium administration can increase the expression of protein phosphatase magnesium dependent 1A (PPM1a), blocking TGF- $\beta$ signaling by dephosphorylating of $\mathrm{p}-\mathrm{Smad} 2 / 3$, and thus preventing the transcription of specific genes needed for HCC growth (9).

Finally, magnesium deficiency in cancer patients increases the risk of cancer metastasis to the liver (82).

\section{Conclusions}

Magnesium status is closely linked with liver function. Liver diseases have a significant effect on body magnesium content, and magnesium levels in turn influence these disease processes. In liver cirrhosis and ALD, patients show magnesium deficiency that results from low dietary uptake, greater urinary secretion, lower plasma albumin concentrations, and hormone inactivation. Conversely, magnesium deficiency aggravates cirrhosis and ALD, and can cause liver cancer progression, due to disrupted mitochondrial function, defective PKC translocation, inflammatory responses, oxidative stress, and metabolic disorders. Magnesium supplementation can not only preserve liver function, but also slow the progression of liver disease, and reduce the mortality associated. Although these findings provide a foundation, there is still a great deal to investigate in this field. Few studies have investigated the relationship between magnesium and HCC or viral hepatitis. In addition, the reason why magnesium deficiency triggers an inflammatory response is still not fully understood, and no clinical studies have explored the therapeutic effects of magnesium in liver patients. In conclusion, this review demonstrates the importance of links between magnesium and liver function or disease, and implies that novel therapeutic approaches targeting magnesium may be used to improve liver function in the future.

\section{Acknowledgments}

Funding: The study was supported by grants from the CAMS Innovation Fund for Medical Sciences (CIFMS) (No. 2016-I2M-1-001) and the National High-tech Research and Development Projects (863) (No. 2015AA020303).

\section{Footnote}

Conflicts of Interest: The authors have no conflicts of interest to declare.

Ethical Statement: The authors are accountable for all aspects of the work in ensuring that questions related to the accuracy or integrity of any part of the work are appropriately investigated and resolved.

\section{References}

1. Blaszczyk U, Duda-Chodak A. Magnesium: Its role in nutrition and carcinogenesis. Rocz Panstw Zakl Hig 2013;64:165-71.

2. Romani AM. Magnesium homeostasis in mammalian cells. Front Biosci 2007;12:308-31.

3. Romani AM. Magnesium homeostasis and alcohol consumption. Magnes Res 2008;21:197-204.

4. Larsson SC, Bergkvist L, Wolk A. Magnesium intake in relation to risk of colorectal cancer in women. JAMA 2005;293:86-9.

5. Saris NE, Mervaala E, Karppanen H, et al. Magnesium. An update on physiological, clinical and analytical aspects. Clin Chim Acta 2000;294:1-26.

6. Delva P. Magnesium and coronary heart disease. Mol Aspects Med 2003;24:63-78. 
7. Mazur A, Maier JA, Rock E, et al. Magnesium and the inflammatory response: Potential physiopathological implications. Arch Biochem Biophys 2007;458:48-56.

8. Adachi M, Brenner DA. Clinical syndromes of alcoholic liver disease. Dig Dis 2005;23:255-63.

9. Liu $\mathrm{Y}, \mathrm{Xu} \mathrm{Y,} \mathrm{Ma} \mathrm{H,} \mathrm{et} \mathrm{al.} \mathrm{Hepatitis} \mathrm{B} \mathrm{virus} \mathrm{X}$ protein amplifies TGF-beta promotion on HCC motility through down-regulating PPM1a. Oncotarget 2016;7:33125-35.

10. Wu L, Zhu X, Fan L, et al. Magnesium intake and mortality due to liver diseases: Results from the third national health and nutrition examination survey cohort. Sci Rep 2017;7:17913.

11. Bataller R, Brenner DA. Liver fibrosis. J Clin Invest 2005;115:209-18.

12. Kar K, Dasgupta A, Vijaya Bhaskar M, et al. Alteration of micronutrient status in compensated and decompensated liver cirrhosis. Indian J Clin Biochem 2014;29:232-7.

13. Nangliya V, Sharma A, Yadav D, et al. Study of trace elements in liver cirrhosis patients and their role in prognosis of disease. Biol Trace Elem Res 2015;165:35-40.

14. Zhao XY, Li J, Wang JH, et al. Vitamin D serum level is associated with child-pugh score and metabolic enzyme imbalances, but not viral load in chronic hepatitis B patients. Medicine (Baltimore) 2016; 95:e3926.

15. Koivisto M, Valta P, Hockerstedt K, et al. Magnesium depletion in chronic terminal liver cirrhosis. Clin Transplant 2002;16:325-8.

16. Rayssiguier Y, Chevalier F, Bonnet M, et al. Influence of magnesium deficiency on liver collagen after carbon tetrachloride or ethanol administration to rats. J Nutr 1985;115:1656-62.

17. Panov A, Scarpa A. Independent modulation of the activity of alpha-ketoglutarate dehydrogenase complex by $\mathrm{Ca} 2+$ and Mg2+. Biochemistry 1996;35:427-32.

18. Panov A, Scarpa A. Mg2 + control of respiration in isolated rat liver mitochondria. Biochemistry 1996;35:12849-56.

19. Palfi A, Toth A, Hanto K, et al. Parp inhibition prevents postinfarction myocardial remodeling and heart failure via the protein kinase c/glycogen synthase kinase-3beta pathway. J Mol Cell Cardiol 2006;41:149-59.

20. Klein G, Schaefer A, Hilfiker-Kleiner D, et al. Increased collagen deposition and diastolic dysfunction but preserved myocardial hypertrophy after pressure overload in mice lacking pkcepsilon. Circ Res 2005;96:748-55.

21. Konno Y, Ohno S, Akita Y, et al. Enzymatic properties of a novel phorbol ester receptor/protein kinase, npkc. J Biochem 1989;106:673-8.

22. Wolf FI, Torsello A, Fasanella S, et al. Cell physiology of magnesium. Mol Aspects Med 2003;24:11-26.

23. Classen CU, Abele C, Schimatschek HF, et al. Erythema formation in magnesium-deficient albino rats. A non-invasive model for the screening of antiinflammatory agents and oral mineral supplements. Arzneimittelforschung 1993;43:672-5.

24. Bois P, Gascon A, Beaulnes A. Histamine-liberating effect of magnesium deficiency in the rat. Nature 1963;197:501-2.

25. Hungerford GF. Role of histamine in producing the eosinophilia of magnesium deficiency. Proc Soc Exp Biol Med 1964;115:182-5.

26. Kraeuter SL, Schwartz R. Blood and mast cell histamine levels in magnesium-deficient rats. J Nutr 1980;110:851-8.

27. Nishio A, Ishiguro S, Ikegaki I, et al. Histamine metabolism and pinnal hyperaemia during magnesium deficiency in rats. Magnes Res 1988;1:155-61.

28. McCreary PA, Battifora HA, Hahneman BM, et al. Leukocytosis, bone marrow hyperplasia and leukemia in chronic magnesium deficiency in the rat. Blood 1967;29 Suppl:683-90.

29. Rude RK, Gruber HE, Wei LY, et al. Magnesium deficiency: Effect on bone and mineral metabolism in the mouse. Calcif Tissue Int 2003;72:32-41.

30. Malpuech-Brugère C, Nowacki W, Daveau M, et al. Inflammatory response following acute magnesium deficiency in the rat. Biochim Biophys Acta 2000;1501:91-8.

31. Malpuech-Brugère $C$, Nowacki $W$, Rock E, et al. Enhanced tumor necrosis factor-alpha production following endotoxin challenge in rats is an early event during magnesium deficiency. Biochim Biophys Acta 1999;1453:35-40.

32. Rayssiguier Y, Mazur A. Magnesium and inflammation: Lessons from animal models. Clin Calcium 2005;15:245-8.

33. Weglicki WB, Phillips TM, Mak IT, et al. Cytokines, neuropeptides, and reperfusion injury during magnesium deficiency. Ann N Y Acad Sci 1994;723:246-57.

34. Altura BM, Gebrewold A, Zhang A, et al. Low extracellular magnesium ions induce lipid peroxidation and activation of nuclear factor-kappa B in canine cerebral vascular smooth muscle: Possible relation to traumatic brain injury and strokes. Neurosci Lett 2003;341:189-92.

35. Malpuech-Brugère C, Rock E, Astier C, et al. Exacerbated immune stress response during experimental magnesium deficiency results from abnormal cell calcium homeostasis. Life Sci 1998;63:1815-22.

36. Iseri LT, French JH. Magnesium: Nature's physiologic 
calcium blocker. Am Heart J 1984;108:188-93.

37. Bussière FI, Gueux E, Rock E, et al. Increased phagocytosis and production of reactive oxygen species by neutrophils during magnesium deficiency in rats and inhibition by high magnesium concentration. Br J Nutr 2002;87:107-13.

38. Bussiere FI, Mazur A, Fauquert JL, et al. High magnesium concentration in vitro decreases human leukocyte activation. Magnes Res 2002;15:43-8.

39. Tracey KJ. The inflammatory reflex. Nature 2002;420:853-9.

40. Kabe Y, Ando K, Hirao S, et al. Redox regulation of NFkappaB activation: Distinct redox regulation between the cytoplasm and the nucleus. Antioxid Redox Signal 2005;7:395-403.

41. Eng FJ, Friedman SL. Fibrogenesis I. New insights into hepatic stellate cell activation: The simple becomes complex. Am J Physiol Gastrointest Liver Physiol 2000;279:G7-11.

42. Gressner AM, Weiskirchen R, Breitkopf K, et al. Roles of TGF-beta in hepatic fibrosis. Front Biosci 2002; 7:d793-807.

43. Schon HT, Weiskirchen R. Immunomodulatory effects of transforming growth factor-beta in the liver. Hepatobiliary Surg Nutr 2014;3:386-406.

44. Schnabl B, Kweon YO, Frederick JP, et al. The role of smad3 in mediating mouse hepatic stellate cell activation. Hepatology 2001;34:89-100.

45. Zhuang RX, Wang FG, Zhou HP, et al. The protective effects of $\mathrm{N}$-acetylcysteine magnesium against liver cirrhosis with portalhypertension in rat. Zhonghua Shi Yan He Lin Chuang Bing Du Xue Za Zhi 2012;26:366-9.

46. Paik YH, Yoon YJ, Lee HC, et al. Antifibrotic effects of magnesium lithospermate b on hepatic stellate cells and thioacetamide-induced cirrhotic rats. Exp Mol Med 2011;43:341-9.

47. Liu S, Zhang H, Gu C, et al. Associations between hepatitis b virus mutations and the risk of hepatocellular carcinoma: A meta-analysis. J Natl Cancer Inst 2009; 101:1066-82.

48. Mann RE, Smart RG, Govoni R. The epidemiology of alcoholic liver disease. Alcohol Res Health 2003;27:209-19.

49. Mandayam S, Jamal MM, Morgan TR. Epidemiology of alcoholic liver disease. Semin Liver Dis 2004;24:217-32.

50. Young A, Cefaratti C, Romani A. Chronic EtOH administration alters liver $\mathrm{Mg} 2+$ homeostasis. Am J Physiol Gastrointest Liver Physiol 2003;284:G57-67.

51. Kalbfleisch JM, Lindeman RD, Ginn HE, et al. Effects of ethanol administration on urinary excretion of magnesium and other electrolytes in alcoholic and normal subjects. J Clin Invest 1963;42:1471-5.

52. Martell AE. Chemistry of the metal chelate compounds. Prentice-Hall: New York 1963;613.

53. Schmitz C, Deason F, Perraud AL. Molecular components of vertebrate $\mathrm{Mg} 2+-$ homeostasis regulation. Magnes Res 2007;20:6-18.

54. Flatman PW. Mechanisms of magnesium transport. Annu Rev Physiol 1991;53:259-71.

55. Günther T, Vormann J. Activation of $\mathrm{Na}+/ \mathrm{Mg} 2+$ antiport in thymocytes by camp. FEBS Lett 1992;297:132-4.

56. Cefaratti C, Romani AM. Functional characterization of two distinct $\mathrm{Mg} 2+$ extrusion mechanisms in cardiac sarcolemmal vesicles. Mol Cell Biochem 2007;303:63-72.

57. Cefaratti C, Romani A, Scarpa A. Differential localization and operation of distinct $\mathrm{Mg} 2+$ transporters in apical and basolateral sides of rat liver plasma membrane. J Biol Chem 2000;275:3772-80.

58. Flink EB. Magnesium deficiency in alcoholism. Alcohol Clin Exp Res 1986;10:590-4.

59. Romani A, Scarpa A. Hormonal control of $\mathrm{Mg} 2+$ transport in the heart. Nature 1990;346:841-4.

60. Romani A, Marfella C, Scarpa A. Regulation of Mg2+ uptake in isolated rat myocytes and hepatocytes by protein kinase c. FEBS Lett 1992;296:135-40.

61. Grubbs RD, Maguire ME. Regulation of magnesium but not calcium transport by phorbol ester. J Biol Chem 1986;261:12550-4.

62. Tessman PA, Romani A. Acute effect of etoh on $\mathrm{Mg} 2+$ homeostasis in liver cells: Evidence for the activation of an $\mathrm{Na} / \mathrm{Mg}$ + exchanger. Am J Physiol 1998;275:G1106-16.

63. Young A, Berti-Mattera L, Romani A. Effect of repeated doses of ethanol on hepatic $\mathrm{Mg} 2+$ homeostasis and mobilization. Alcohol Clin Exp Res 2007;31:1240-51.

64. Lüthi D, Gunzel D, McGuigan JA. Mg-ATP binding: Its modification by spermine, the relevance to cytosolic $\mathrm{Mg} 2+$ buffering, changes in the intracellular ionized $\mathrm{Mg} 2+$ concentration and the estimation of $\mathrm{Mg} 2+$ by 31P-NMR. Exp Physiol 1999;84:231-52.

65. Cefaratti C, Young A, Romani A. Effect of ethanol administration on $\mathrm{Mg} 2+$ transport across liver plasma membrane. Alcohol 2005;36:5-18.

66. Fukui H, Brauner B, Bode JC, et al. Plasma endotoxin concentrations in patients with alcoholic and non-alcoholic liver disease: Reevaluation with an improved chromogenic assay. J Hepatol 1991;12:162-9.

67. Adachi M, Ishii H. Role of mitochondria in alcoholic liver 
injury. Free Radic Biol Med 2002;32:487-91.

68. Thurman RG. II. Alcoholic liver injury involves activation of kupffer cells by endotoxin. Am J Physiol 1998;275:G605-11.

69. Weiskirchen R, Tacke F. Cellular and molecular functions of hepatic stellate cells in inflammatory responses and liver immunology. Hepatobiliary Surg Nutr 2014;3:344-63.

70. Poikolainen K, Alho H. Magnesium treatment in alcoholics: a randomized clinical trial. Subst Abuse Treat Prev Policy 2008;3:1.

71. Gueux E, Mazur A, Cardot P, et al. Magnesium deficiency affects plasma lipoprotein composition in rats. J Nutr 1991;121:1222-7.

72. Nassir F, Mazur A, Giannoni F, et al. Magnesium deficiency modulates hepatic lipogenesis and apolipoprotein gene expression in the rat. Biochim Biophys Acta 1995;1257:125-32.

73. Khovidhunkit W, Kim MS, Memon RA, et al. Effects of infection and inflammation on lipid and lipoprotein metabolism: Mechanisms and consequences to the host. J Lipid Res 2004;45:1169-96.

74. Barbagallo M, Dominguez LJ, Galioto A, et al. Role of magnesium in insulin action, diabetes and cardio-metabolic syndrome X. Mol Aspects Med 2003;24:39-52.

75. Huerta MG, Roemmich JN, Kington ML, et al. Magnesium deficiency is associated with insulin resistance in obese children. Diabetes Care 2005;28:1175-81.

Cite this article as: Liu MX, Yang HY, Mao YL. Magnesium and liver disease. Ann Transl Med 2019;7(20):578. doi: 10.21037/ atm.2019.09.70
76. Busserolles J, Gueux E, Rock E, et al. High fructose feeding of magnesium deficient rats is associated with increased plasma triglyceride concentration and increased oxidative stress. Magnes Res 2003;16:7-12.

77. Chaudhary DP, Boparai RK, Sharma R, et al. Studies on the development of an insulin resistant rat model by chronic feeding of low magnesium high sucrose diet. Magnes Res 2004;17:293-300.

78. Tukiendorf A, Rybak Z. New data on ecological analysis of possible relationship between magnesium in drinking water and liver cancer. Magnes Res 2004;17:46-52.

79. Liu Y, Li X, Zou Q, et al. Inhibitory effect of magnesium cantharidate on human hepatoma SMMC-7721 cell proliferation by blocking MAPK signaling pathway. Xi Bao Yu Fen Zi Mian Yi Xue Za Zhi 2017;33:347-51.

80. El-Serag HB, Rudolph KL. Hepatocellular carcinoma: Epidemiology and molecular carcinogenesis. Gastroenterology 2007;132:2557-76.

81. Kopański Z, Piekoszewski W, Schlegel-Zawadzka M, et al. The importance of determination of magnesium concentration in the serum of patients with cancer metastases to the liver. Przegl Lek 2002;59:267-8.

82. Frick DN, Banik S, Rypma RS. Role of divalent metal cations in ATP hydrolysis catalyzed by the hepatitis $\mathrm{C}$ virus NS3 helicase: Magnesium provides a bridge for ATP to fuel unwinding. J Mol Biol 2007;365:1017-32. 